\title{
Performance of railway track system under harmonic loading by finite element method
}

\author{
Ammar Shuber ${ }^{1}$, Mohammed Hamood ${ }^{1,{ }^{*}}$ and Walaa Jawad ${ }^{1}$ \\ ${ }^{1}$ Building and Construction Engineering Department, University of Technology, Baghdad, Iraq
}

\begin{abstract}
The performance of railway track under dynamic loading depends on many parameters such as type of sleepers, ballast, soil - structure interaction and the relation of contact forces between the track and railway. The rail track classified as low and high speeds, where speed is a very important factor in design. Many theoretical models were derived and some developed for dynamic analysis of railway track system with assumptions that simplified or matched actually the real behavior especially the support of sleepers as linear or nonlinear and the contact between railway and track. In the present paper, a Finite Elements Approach is one of the numerical analysis by ANSYS software that adopted here to study the performance of harmonic analysis of railway track system. Harmonic ranges were applied with constant applied loading based on the European code for the steel rail.
\end{abstract}

\section{Introduction}

Rail is the most important part of the whole system of train railway, made from steel. The functions of rail are to transmute the weight of the train to the lower components, guide the wheels and give smooth surface for running. Sleepers are another part typically made from timber, concrete, steel and other alternate materials, the functions of sleepers are to cushion and transfer external loads to the ballast. Ballast used to fix and anchors the sleepers, resists the lateral and vertical forces which come from train, that means provides stability, also distributes the loads to the subgrade layers. Subgrade layers are designed to resist all loads from the components of railway system and rest on hard soil to prevent any unexpected failure. Rail joints that are made from angle bars are used to hold the ends of the rail in the right place and worked as beam and to prevent vertical and horizontal movements of the rail.

In 2009, Jabbar Ali Zakeri and He Xia [1], adopted (FEA) to analyze two dimensional beam element (Timoshenko beam) that represented railway and concerned the train - track interaction under the effect of dynamic loading. In 2009, Valeri Markine et al [2], looked closely at the relationships between railway pads, sleeper's pad and ballast foundation with applied dynamical loading from tracks, and investigated the relationship between wheel, rail and dynamic loading by using FEM. In 2010, A. Gomes Correia et al [3], studied many softwares that deal with Finite Elements approach to simulate and evaluate the performance of railway in case of high speed of track train and used the data in all softwares from the available experiments. In 2011, Khanh Nguyen et al [4], reported and studied the loading on ballast under the effects of dynamic loading in case of high speed. In 2011, Huan Feng [5], studied the effects of many parameters on the design of railway system under dynamic loading. Finite Elements Approach was considered in the study and many models were simulated that described the relation between beams, soil, ballast, sleepers and railway track system. Euler-Bernoulli principle was adopted to simulate rail and sleepers; spring model was used to represent the relationship between sleepers and ballast. In 2012, Puguh B. Prakoso [6], used conventional method and compared the results by using another approached as (FEM) to model the whole track system. Beam rest on the elastic foundation that adopted the concept of Winkler's theory is the conventional approach that was classified as one dimensional as it still has lack of applications for railway analysis. FEM also adopted by ANSYS software to model the railway track system and compared the results with Zimmermann Method. In 2014, D. Kishore Kumar and K. Sambasivarao [7], studied the performance of prestressed concrete sleepers under static and impact loading by modeling the problem using Finite Elements Method (FEM). Natural frequency was calculated under various supports condition such as free or fixed. In 2014, A. Ortega García [8], investigated the dynamic behavior of railway track. The frequency due to the vibrations caused by track was analyzed using numerical approach and divided in two parts, first, simulated the railway track using FEM, and the second, checked out the safety of the track according to vertical displacements due to velocity.

\footnotetext{
* Corresponding author: mih smm@yahoo.com
} 
In 2016, Zhenxing He and Xinwen Yang [9], studied the performance of sleepers by coupled vehicle-track system under dynamic loading. Three dimensional models were used for two-block sleeper. All external loading that developed from car, frames and wheel was assumed rigid.

Too many approaches were considered and adopted to analyze the railway system. In present work Finite Elements Analysis (FEA) has been adopted. Analysis has been done using two dimensions that requires to make some assumptions to reduce the complexity of the problem. Three dimensions simulation using finite elements analysis represent the actual behaviors of the problem by taking into account all parameters that affects the performance of the railway system. By selecting suitable elements to represent the real characteristics of each parameters, elements size, real input data, suitable solver and good accuracy lead to accurate results, so selection of three dimensions was done to simulate the railway system to ensure that the problem gets solved correctly.

\section{Modeling}

Railway track, sleepers, ballast and soil layers were taken into account to simulate the whole railway track system. The model consists of a discrete system of springs, dampers and masses that take into account the parameters effects on the performance of railway track system.

Numerical approach is adopted for railway track system performance. Finite Elements Approach depends on the assumed strain field and the degree of freedoms for each nodes when analysis is three dimensional and then the equations are formed in matrix form to find the unknowns.

In two dimensional approach of (FEA), the rail track represented as beam element has two degrees of freedom at each node at the ends, vertical displacement and rotation $(\mathrm{u}, \vartheta)$ as follow:

$$
\left\{y_{i}\right\}=\left\{u_{i} \vartheta_{i}\right\}
$$

The relationship between the forces and the displacements is expressed by the equation below:

$$
\{F\}^{e}=[k]^{e}\{y\}^{e}
$$

Where, $(\mathrm{k})$ is the stiffness matrix for each element and then after assembly in one stiffness matrix as global matrix. The mass matrix formed by the sum for all masses defined as:

$$
[m]=\left[\begin{array}{cccc}
m_{1} & 0 & \ldots & 0 \\
0 & m_{2} & \ldots & 0 \\
\ldots & \ldots & \ldots & \ldots \\
0 & 0 & \ldots & m_{n}
\end{array}\right.
$$

(c) which defined as damping matrix as follow:

$$
[c]^{e}=\lambda[m]^{e}+\gamma[k]^{e}
$$

Where, $(\lambda)$ and $(\gamma)$ are damping confections. The general equation that collects all parameters based on the Newton's second law, so:

$$
[M]\left\{y_{r}^{\prime \prime}\right\}+[c]\left\{y_{r}^{\prime}\right\}+[k]\left\{y_{r}\right\}=\{q\}
$$

Where, $[\mathrm{M}]$, is the sum of all masses, $[\mathrm{c}]$, is the sum for all damping coefficients, $[\mathrm{k}]$, is the sum for all stiffnesses and $\{\mathrm{q}\}$ is the sum for all foresees, $\{\mathrm{yr}\},\left\{\mathrm{yr}^{\prime}\right\}$ and $\left\{\mathrm{yr}^{\prime \prime}\right\}$ are the displacement, velocity and acceleration of the rail, respectively. The relations between all elements as finite elements after construction of the assembly matrix that contains all parameters. The three dimensional finite elements differ from the two dimensions because the degrees of freedom become more and the problem becomes more complex.

\subsection{Assumptions}

The assumptions adopted in present study are listed below:

- Concrete as sleepers, steel as railway and all others materials are modeled as isotropic and homogeneous.

- Steel was assumed to be an elastic-perfectly plastic material and identical in tension and compression (no hardening).

-Initially plane sections remain plane after loading (no nonlinear geometry).

-The maximum compressive strain in the concrete is assumed to be $0.003 \mathrm{~mm} / \mathrm{mm}$.

-Perfect bond exits between different materials.

-Self-weight of all materials is ignored.

The ANSYS [10] program is one of the most powerful and versatile that is adopted in the present study. It is effective and efficient, especially for harmonic load analysis. The reinforcement in the discrete model uses one dimensional bar that is connected to same concrete mesh nodes so that makes integrity and there is no friction between them. Full displacement compatibility between the reinforcement and concrete is a significant advantage of the discrete representation, see Figure (1).

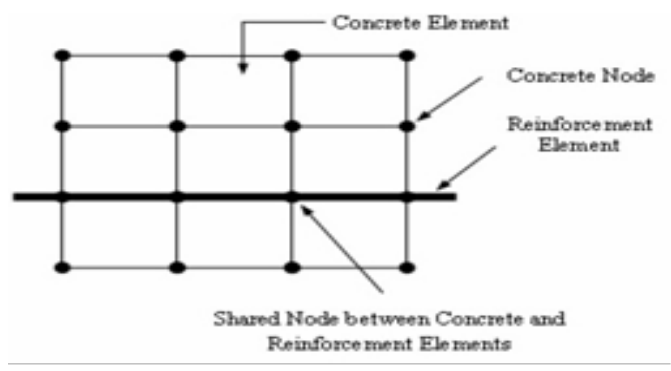

Fig.(1). Reinforcements representation 


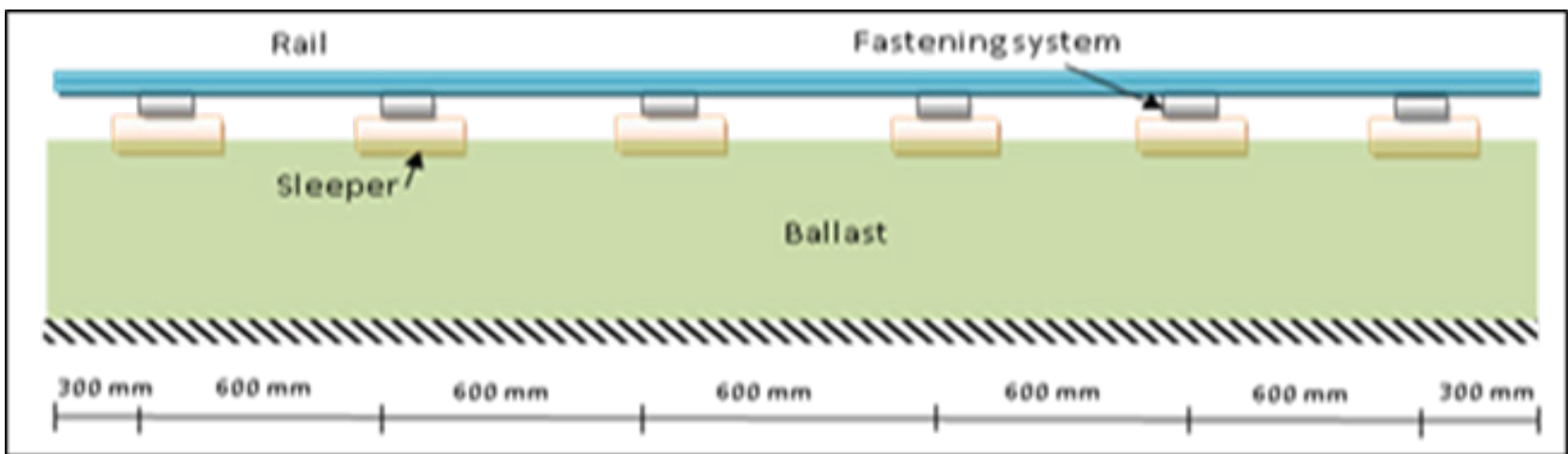

Fig. (2). Section in railway track system

\subsection{Simulations and loading}

For railway steel I section, SOLID185 is selected. The element is defined with eight nodes having three degrees of freedom at each node - translations in the nodal $\mathrm{x}, \mathrm{y}$, and $\mathrm{z}$ directions. The SOLID65 element is used to model concrete sleepers. This element has eight nodes with three degrees of freedom at each node - translations in the nodal $\mathrm{x}, \mathrm{y}$, and $\mathrm{z}$ directions. Link180 element is used to model steel reinforcement. This element is a 3D spar element and it has two nodes with three degrees of freedom at each node - translations in the nodal $\mathrm{x}, \mathrm{y}$ and $\mathrm{z}$ directions. The use of a square (aspect ratio equal to unity) or rectangular mesh is recommended for good accuracy and saving time, so that the mesh is set up such that square or rectangular elements are created.

The magnitude of applied loading based on the load adopted by European code at the nodes along the railway that represents the train loading. Fixed supports are assumed at the bottom of sleepers to simulate the ballast layer and rock bed.

Harmonic response analysis is a linear analysis and the full method is adopted here which considers all matrix elements and calculates all displacements and stresses in a single pass.

\section{Definition of the model}

A section of a railway track system as shown in Figure (2) is modeled using (FEA) by ANSYS. The reduced number of elements in the model allows simplifying the numerical works performed by the (FEA), so that only one single railway will consider.

Table (1) lists the symbols mark, loading type, frequency range, and sleeper's status.

\subsection{Geometry}

The model is made up of $(12000 \mathrm{~mm})$ total classic railway track represented with varied structural element in three dimensional models. Each element has material and geometrical properties according to their function in the superstructure. The cross sectional for railway is UIC -60 as shown in the Figure (3), the type of connections between railway and the sleepers are rigid connection, the sleeper cross section shown in the Figure (4).

Table (1). Model classifications

\begin{tabular}{|c|c|c|c|c|}
\hline $\begin{array}{l}\text { Model } \\
\text { mark }\end{array}$ & Loading & $\begin{array}{l}\text { Frequency } \\
\text { range }(\mathrm{Hz})\end{array}$ & $\begin{array}{c}\text { Loading } \\
(\mathrm{kN})\end{array}$ & $\begin{array}{c}\text { Sleepers } \\
\text { status }\end{array}$ \\
\hline RW1 & Static & --- & $\begin{array}{c}\text { Euro } \\
\text { loading }\end{array}$ & Normal \\
\hline RW2 & Static & --- & $\begin{array}{c}\text { Euro } \\
\text { loading }\end{array}$ & $\begin{array}{c}\text { Two } \\
\text { sleepers fail }\end{array}$ \\
\hline RW3 & Static & --- & $\begin{array}{c}\text { Euro } \\
\text { loading }\end{array}$ & $\begin{array}{c}\text { Three } \\
\text { sleepers fail }\end{array}$ \\
\hline RW4 & Static & --- & $\begin{array}{c}\text { Euro } \\
\text { loading }\end{array}$ & $\begin{array}{c}\text { Four } \\
\text { sleepers fail }\end{array}$ \\
\hline RW5 & Low & $0-40$ & $\begin{array}{c}\text { Euro } \\
\text { loading }\end{array}$ & Normal \\
\hline RW6 & Low & $0-40$ & $\begin{array}{c}\text { Euro } \\
\text { loading }\end{array}$ & $\begin{array}{c}\text { Two } \\
\text { sleepers fail }\end{array}$ \\
\hline RW7 & Low & $0-40$ & $\begin{array}{c}\text { Euro } \\
\text { loading }\end{array}$ & $\begin{array}{c}\text { Three } \\
\text { sleepers fail }\end{array}$ \\
\hline RW8 & Low & $0-40$ & $\begin{array}{c}\text { Euro } \\
\text { loading }\end{array}$ & $\begin{array}{c}\text { Four } \\
\text { sleepers fail }\end{array}$ \\
\hline RW9 & Medium & $40-400$ & $\begin{array}{c}\text { Euro } \\
\text { loading }\end{array}$ & Normal \\
\hline RW10 & Medium & $40-400$ & $\begin{array}{c}\text { Euro } \\
\text { loading }\end{array}$ & $\begin{array}{c}\text { Two } \\
\text { sleepers fail }\end{array}$ \\
\hline RW11 & Medium & $40-400$ & $\begin{array}{c}\text { Euro } \\
\text { loading }\end{array}$ & $\begin{array}{c}\text { Three } \\
\text { sleepers fail }\end{array}$ \\
\hline RW12 & Medium & $40-400$ & $\begin{array}{c}\text { Euro } \\
\text { loading }\end{array}$ & $\begin{array}{c}\text { Four } \\
\text { sleepers fail }\end{array}$ \\
\hline
\end{tabular}

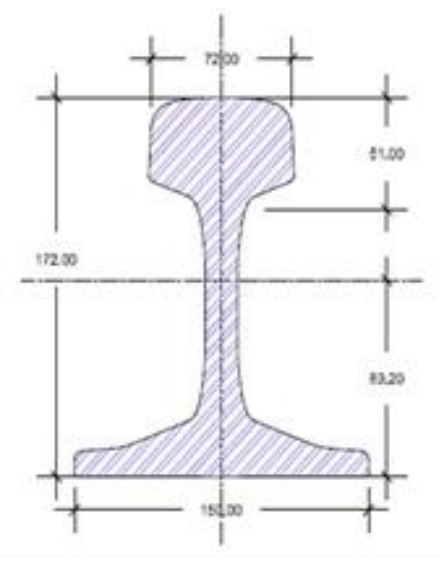

Fig. (3). UIC-60 cross section

*Corresponding author: mjh_smm@yahoo.com 


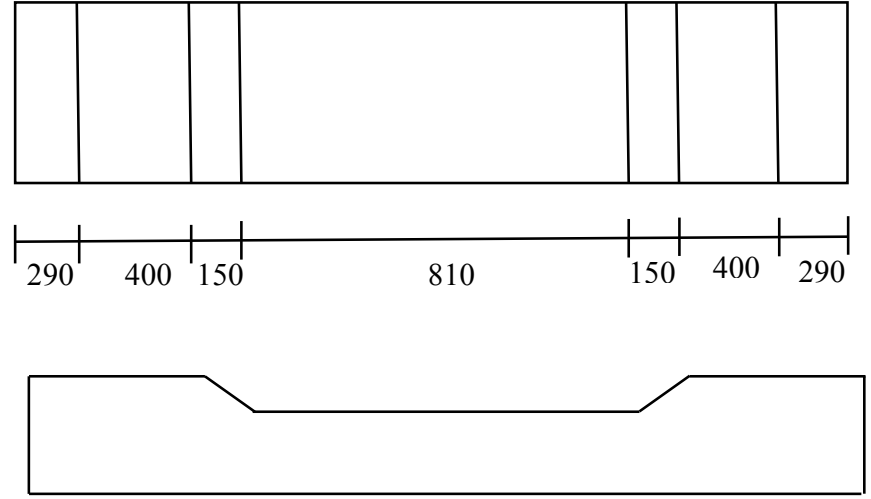

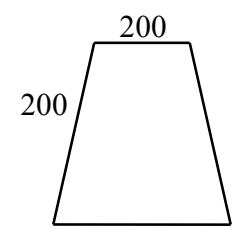

300

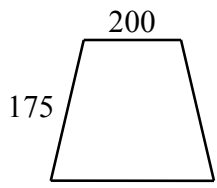

300
Fig. (4). Sleeper cross section. (All dimensions in $\mathrm{mm}$ )

\subsection{Elements type}

For railway steel I section, SOLID185 is select. The element is defined with eight nodes having three degrees of freedom at each node - translations in the nodal $\mathrm{x}, \mathrm{y}$, and $\mathrm{z}$ directions. The geometry and node locations for this element type are shown in Figure (5).

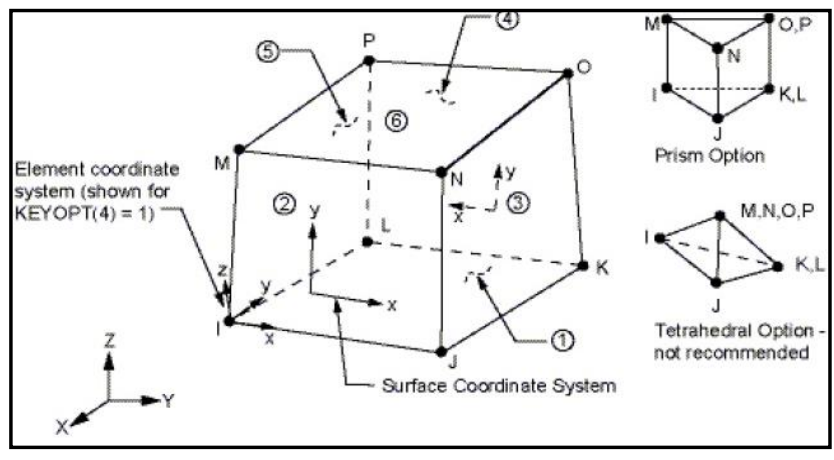

Fig. (5). SOLID185 element

The Solid65 element is used to model concrete sleepers. This element has eight nodes with three degrees of freedom at each node - translations in the nodal $x, y$, and $z$ directions. This element is capable for cracking and crushing in three normal directions. A schematic of the element is shown in Figure (6).

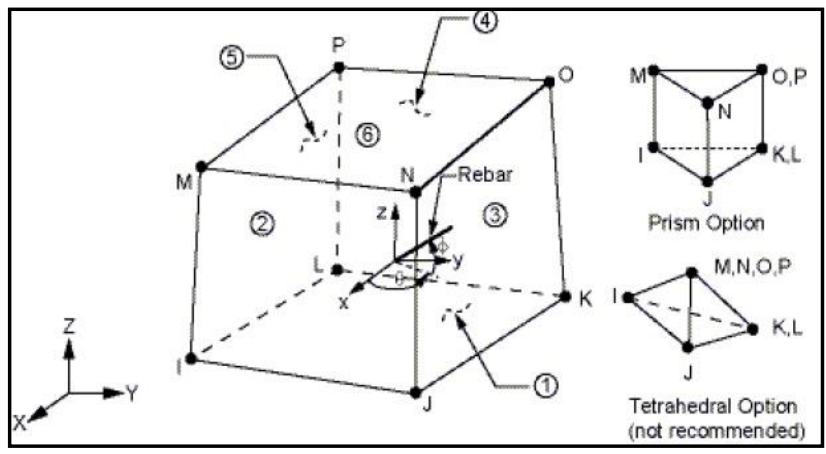

Fig. (6). SOLID65 element

Link180 element is used to model steel reinforcement. This element is a 3D spar element and it has two nodes with three degrees of freedom at each node - translations in the nodal $\mathrm{x}, \mathrm{y}$ and $\mathrm{z}$ directions see Figure (7).

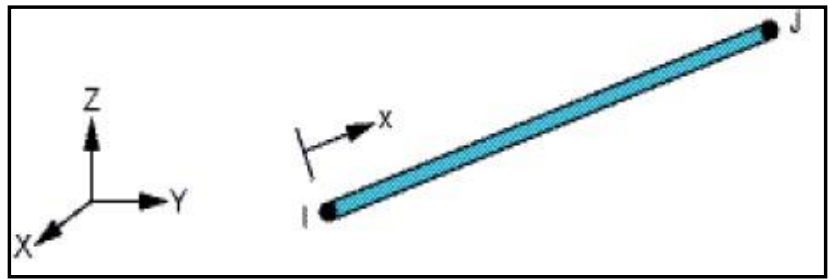

Fig. (7). Link180 element

The real constant and material properties like modulus of elasticity, Poisson's ratio for each element are used as input data to complete the model.

\subsection{Meshing}

The use of a square (aspect ratio equal to unity) or rectangular mesh is recommended for good accuracy and time saving, so that the mesh is set up such that square or rectangular elements were created. A convergence study was carried out to determine an appropriate mesh density. No need to mesh the reinforcement because of the link element created at the same nodes of concrete.

\subsection{Loading}

The loading of the track comes from the moving wheel, which is loaded by a constant force dead load of the car. The vertical actions used for Railway Bridge according to EURO code are defined by means of load models as shown in Figure (8). 


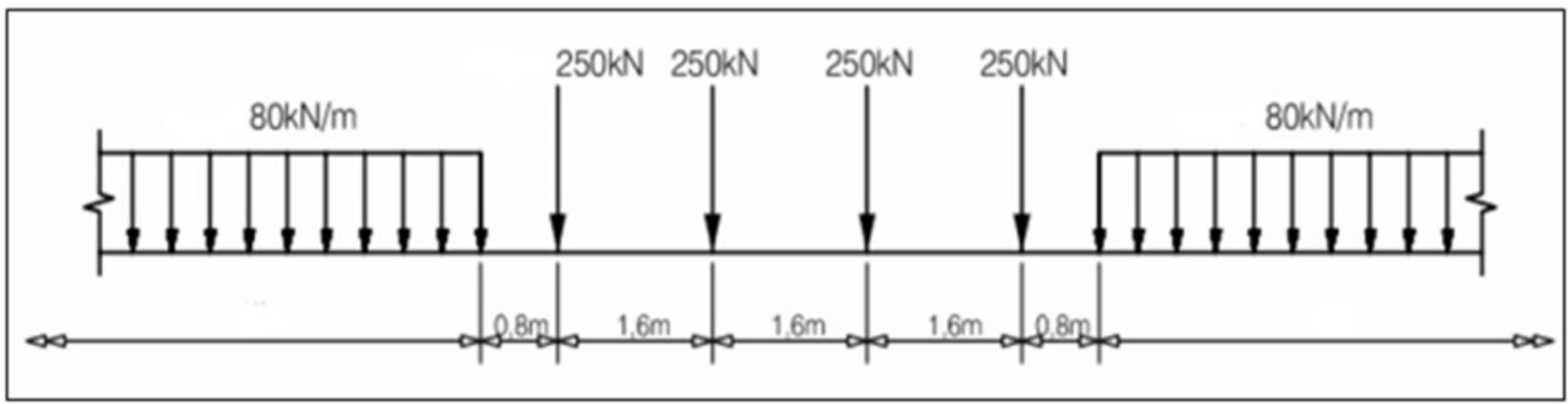

Fig. (8). Load Model and characteristic values for vertical loads

\section{Sleeper's failure}

The ehaviour of the soil is not exactly the same under all sleepers; also the loading of the track is irregular, so that the amount of settlement will differ from one sleeper to another. Because of the reasons mentioned above the sleepers are not always fully supported, and some sleepers may even become completely unsupported (voided) and a gap appears between the sleeper and the ballast layer. At the zone of failure, the track geometry starts to deteriorate, the variations of the train/track interaction force increase, and this speeds up the track deterioration rate.

\section{Analysis}

The finite elements model for normal case (no sleepers fail) is shown in Figure (9), and the finite model is shown in Figure (10). Figure (11) shows the three dimensional railway track system in case of two, three and four sleepers failure locations.

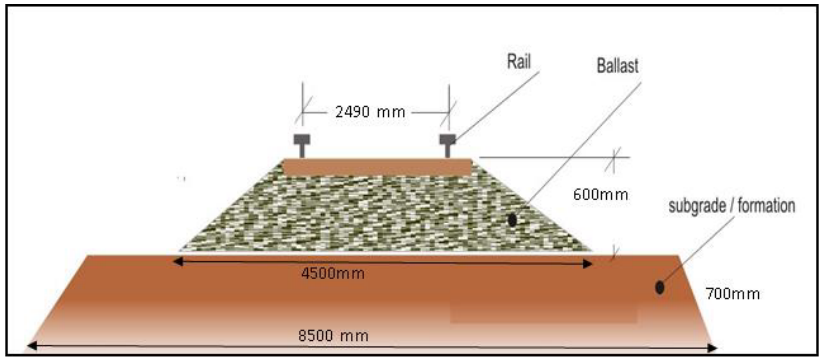

Fig. (9). The actual geometry of the railway system

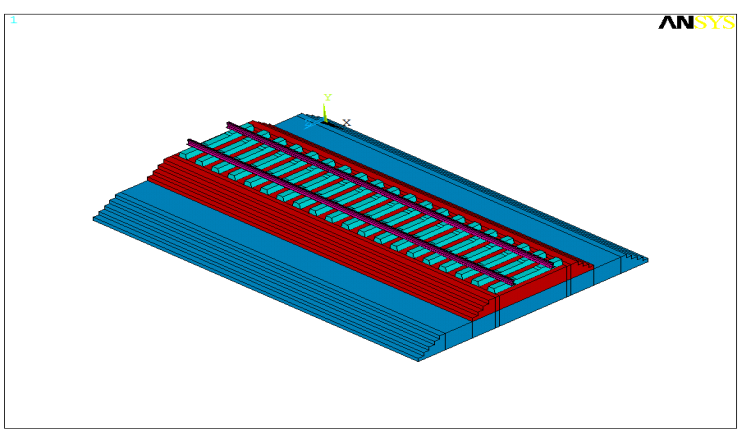

Fig. (10). Three dimensional view of normal railway system

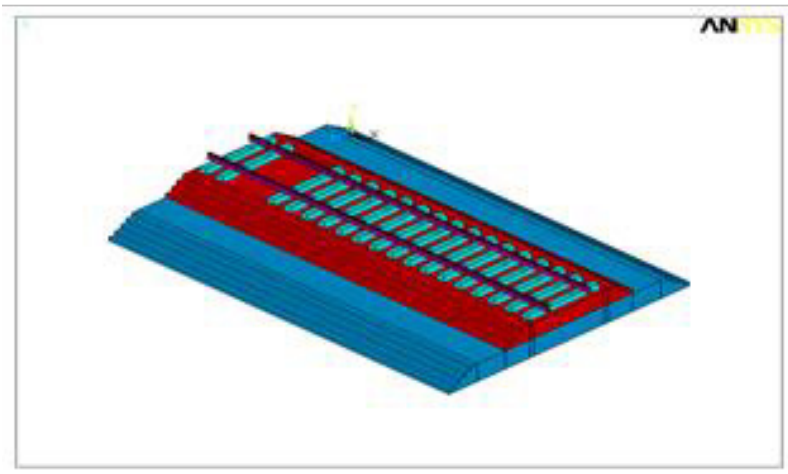

( a )

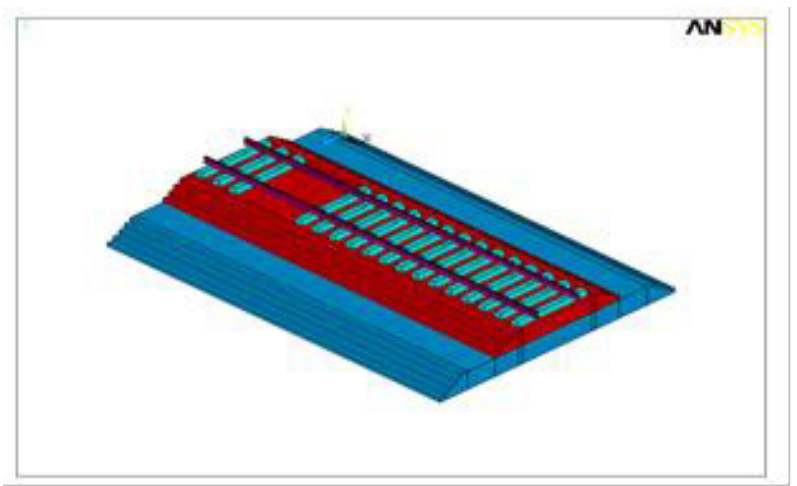

( b )

\footnotetext{
* Corresponding author: mjh smm@yahoo.com
} 


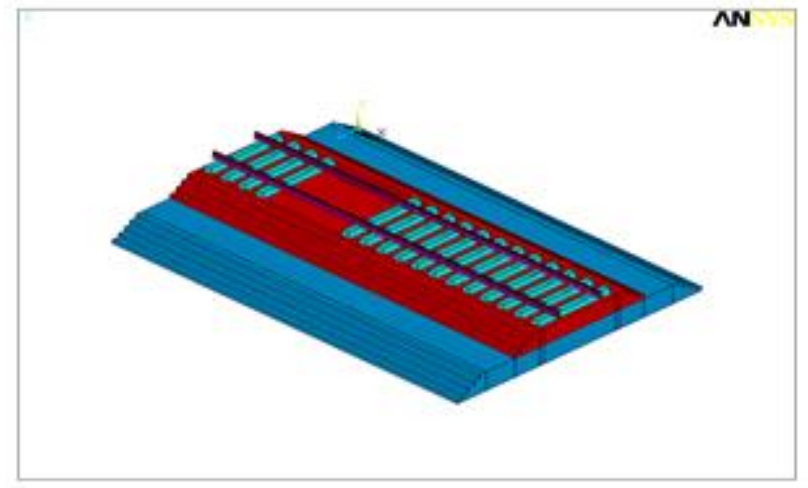

(c)

Fig. (11). Three dimensional and of two, three and four sleepers failure locations for railway system

The analysis results from ANSYS modeling shown in Figures (12) to (14) while the modeling represent the full performance of whole railway track system for three and four that fail under static loading.

In case of dynamic - harmonic loading analysis, the deflection - frequency for railway system in case of no sleep failure is shown in Figure (15). Figures (16) to (19) represented the performance of railway system under low harmonic loading in the range of $(0-40 \mathrm{~Hz})$. In case of medium frequency range $(40-400 \mathrm{~Hz})$, Figures (20) to (25) showed the full performance of the railway system for all cases.

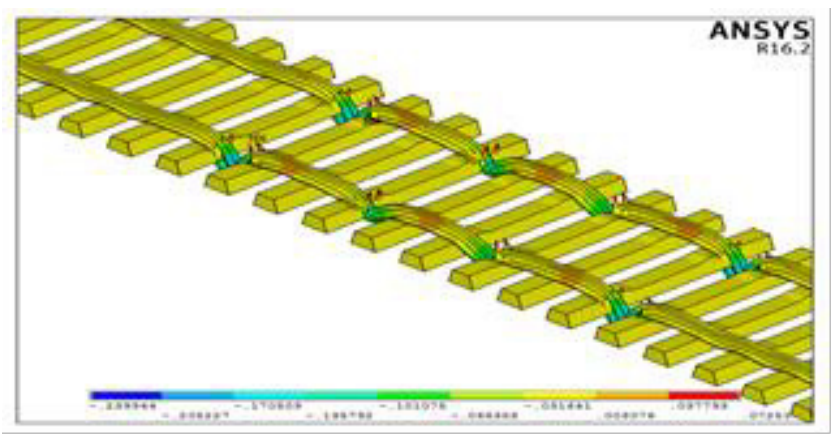

Fig. (12). Deflection of railway track system

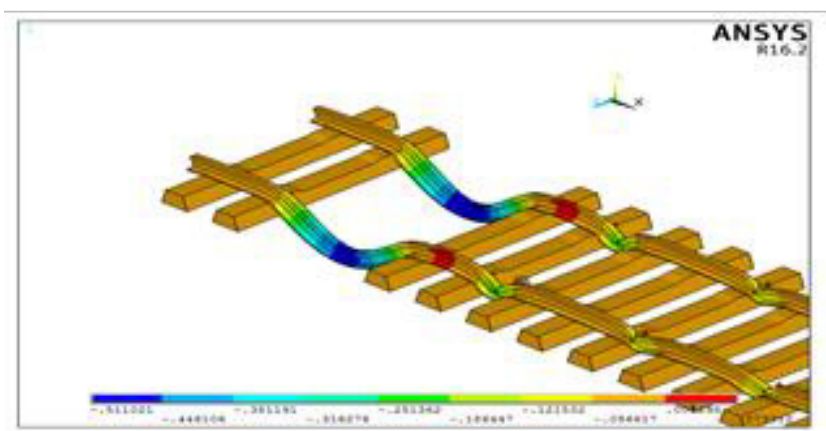

Fig. (13). Deflection of railway track system in case of failure of two sleepers

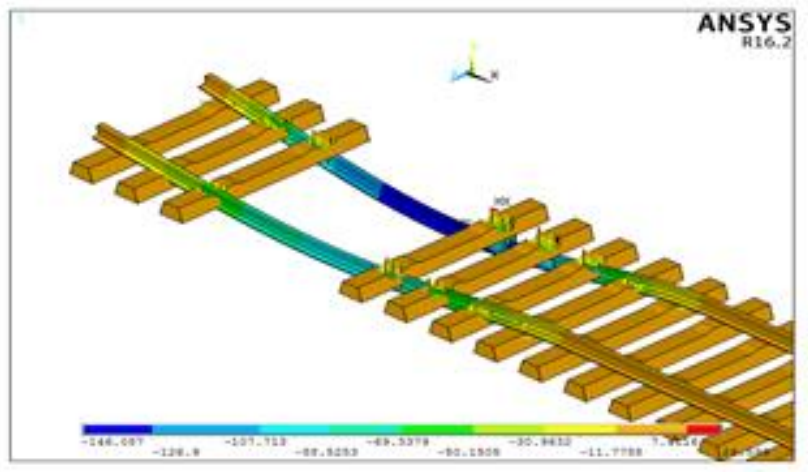

Fig. (14). Deflection of railway track system in case of failure of three sleepers

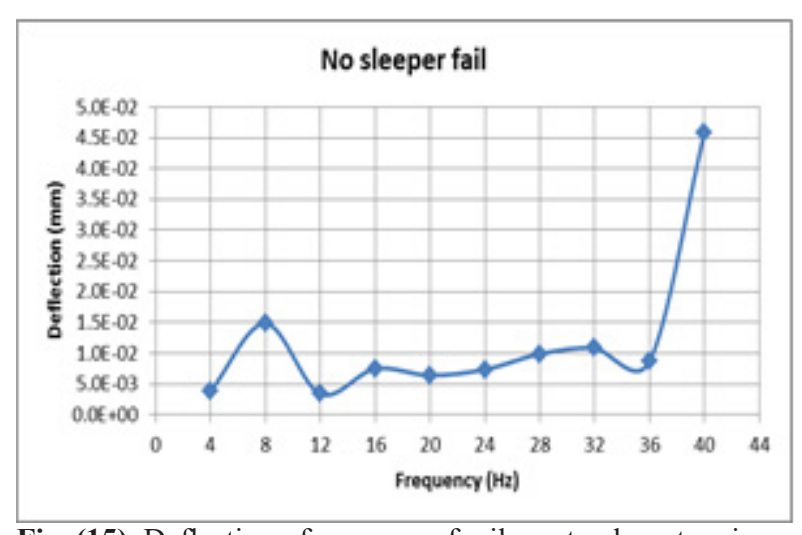

Fig. (15). Deflection -frequency of railway track system in case of failure of no sleeper failure

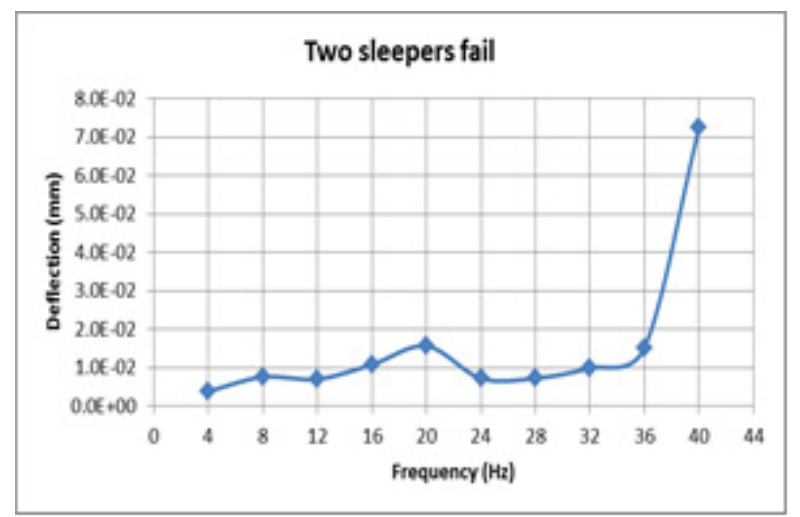

Fig. (16). Deflection -frequency of railway track system in case of failure of two sleeper failure

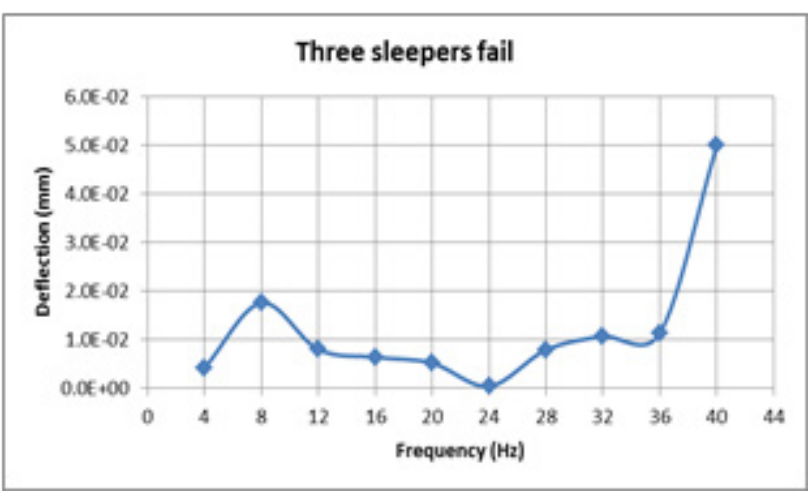

Fig. (17). Deflection -frequency of railway track system in case of failure of three sleeper failure. 


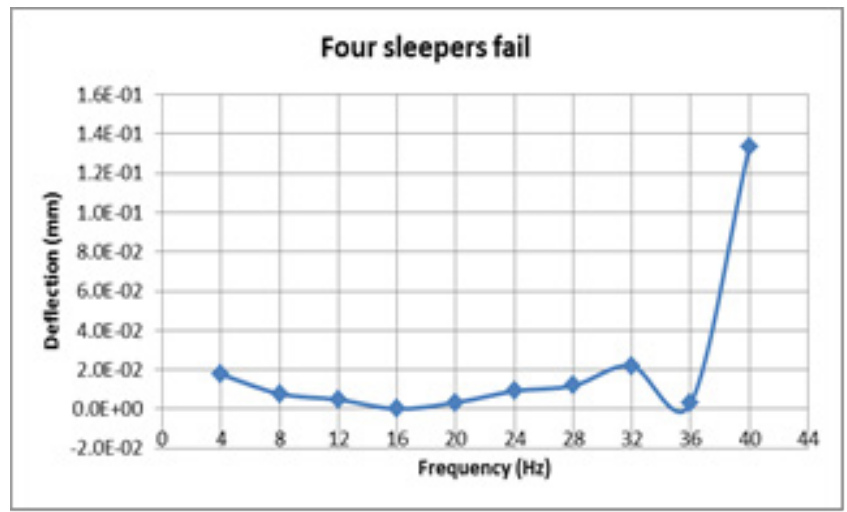

Fig. (18). Deflection -frequency of railway track system in case of failure of four sleeper failure.

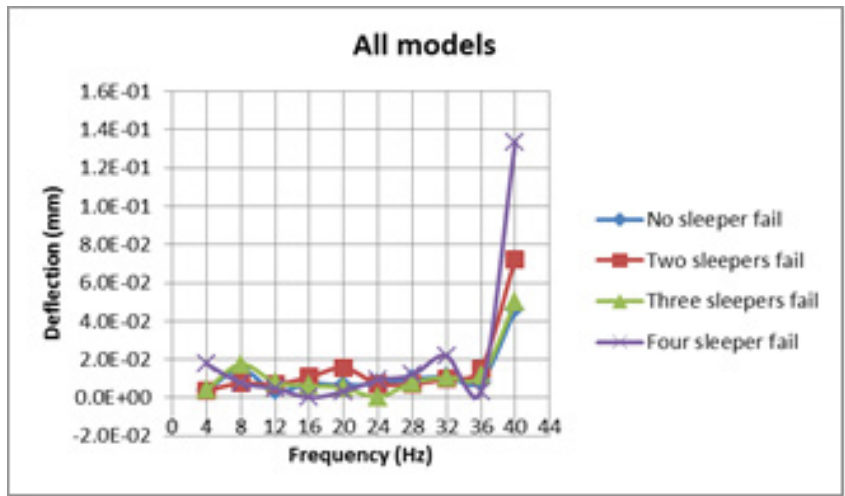

Fig. (19). Deflection -frequency of railway track system all models

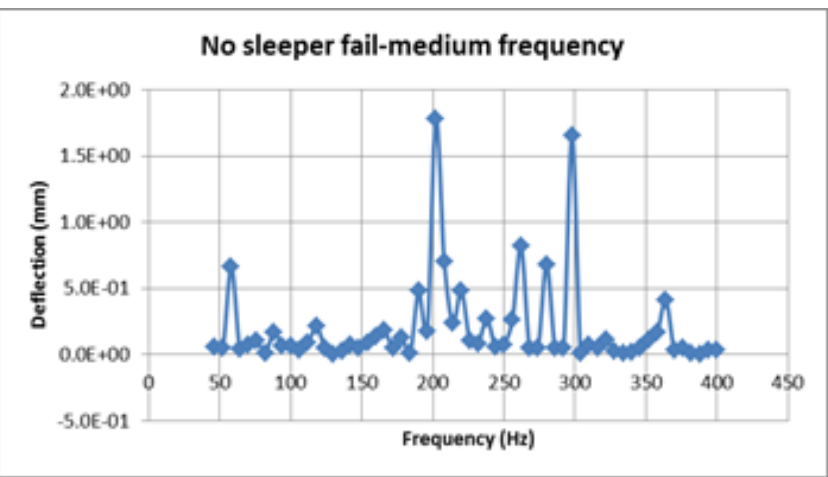

Fig. (20). Deflection -frequency of railway track system in case of failure of no sleeper failure.

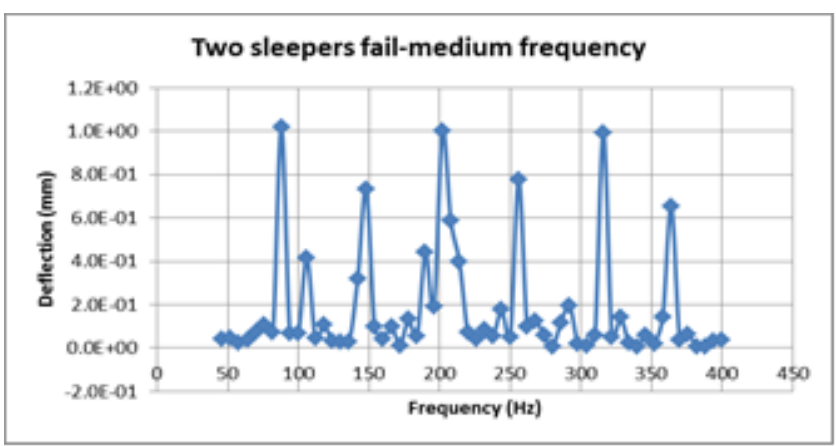

Figure (21): Deflection -frequency of railway track system in case of failure of two sleeper failure

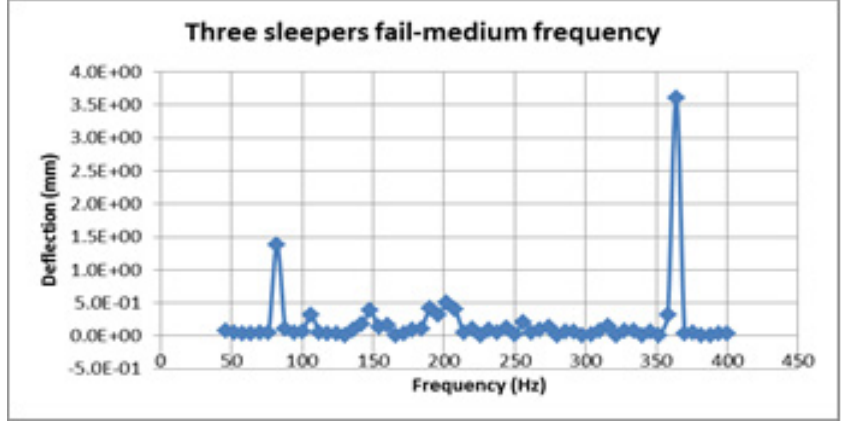

Figure (22): Deflection -frequency of railway track system in case of failure of three sleeper failure

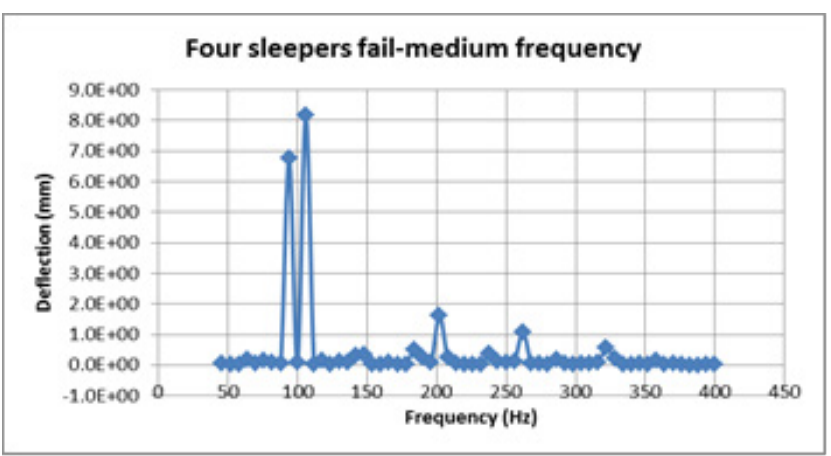

Fig. (23). Deflection -frequency of railway track system in case of failure of four sleeper failure

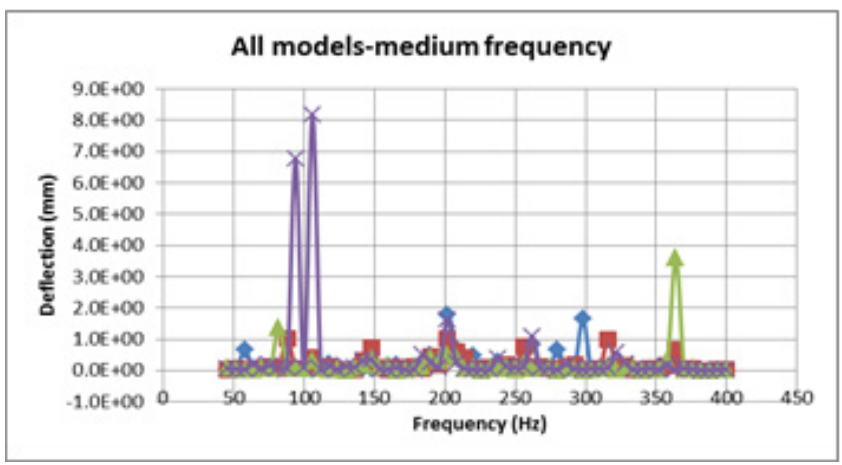

Fig. (24). Deflection -frequency of railway track system all models

\section{Conclusions}

Based on the finite elements analysis by ANSYS, the following points may be drawn:

- The static analysis of the whole railway track system successful for normal and two failures of sleeper cases because of the deflection within limit (less than $1.67 \mathrm{~mm}$ if assumed behaved as simply supported beam). - In case of three and four failures of sleeper cases, the railway fails because of increase in deformation values, so that it concluded that the fail will occur in case of span failure equal and more than $1.8 \mathrm{~m}$.

- In case of harmonic loading, the low range at frequency equal to $(40 \mathrm{~Hz})$ the deflection becomes higher but less than the limit in case of static loading.

- In case of harmonic loading, the low range at frequency equal to $(40 \mathrm{~Hz})$ the deflection becomes higher 
but different in values based on the number of failures of sleepers.

- In case of harmonic loading, the medium range at frequency equal to $(200,200$ with other ranges, 370, and $110 \mathrm{~Hz}$ ) in case of normal, two, three and four failure of sleepers, the deflection becomes higher but less than the limit in case of static loading.

\section{References}

1. Jabbar Ali Zakeri and He Xia, "Application of 2Dinfinite beam elements in dynamic analysis of traintrack interaction", Journal of Mechanical Science and Technology, 23, (2009), 1415 1421.

2. Valeri Markine et al, "A dynamic model for analysis of damage of railways switches", International Symposium on dynamics of vechiles on roads and tracks , 2009, Sweden, 1-13.

3. A. Gomes Correia et al, " Dynamic analysis of rail track for high speed trains. 2D approach", Foundation for Science and Technology (FCT), (project POCI/ECM/61114/2004 - Interaction soilrailway track for high speed trains), 2010.

4. Khanh Nguyen et al, "Dynamic Analysis of High Speed Railway Traffic Loads on Ballasted Track", Advances in Environmental Vibration, Fifth International Symposium on Environmental Vibration, Chengdu, China, October 20-22, 2011.
5. Huan Feng, "3D models of railway track for dynamic analysis", Master Degree Project, Division of Highway and Railway Engineering, Department of Transport Science, School of Architecture and the Built Environment, Royal Institute of Technology, SE-100 44 Stockholm, Stockholm 2011.

6. Puguh B. Prakoso, "The Basic Concepts of Modeling Railway Track Systems Using Conventional and Finite Element Methods", INFO

7. D.Kishore Kumar and K.Sambasivarao, "Static and Dynamic Analysis of Railway Track Sleeper", International Journal of Engineering Research and General Science Volume 2, Issue 6, OctoberNovember, 2014

8. A. Ortega García, " Numerical and experimental analysis of the vertical dynamic behavior of a railway track", Master of Science Thesis, University of Technology, 24 April 2014.

9. Zhenxing He and Xinwen Yang, "Dynamic Response Analysis of an Asymmetric Coupled Vehicle-Track System Generated by Voided Elastic Two-Block Sleeper", Hindawi Publishing Corporation, Shock and Vibration, Volume 2016, Article ID 4985265, 11 pages

10. ANSYS, Inc. Help Manual: is a UL registered ISO 9001:2000 Company. Version (16.2), 2016, USA. 